\title{
The ground-level ozone concentration is inversely correlated with the number of COVID-19 cases in Warsaw, Poland
}

\author{
Oskar Wiśniewski ${ }^{1}$ (D) Wiesław Kozak ${ }^{1}$ - Maciej Wiśniewski ${ }^{2}$ \\ Received: 24 September 2020 / Accepted: 16 March 2021 / Published online: 8 April 2021 \\ (C) The Author(s) 2021
}

\begin{abstract}
COVID-19, which is a consequence of infection with the novel viral agent SARS-CoV-2, first identified in China (Hubei Province), has been declared a pandemic by the WHO. As of September 10, 2020, over 70,000 cases and over 2000 deaths have been recorded in Poland. Of the many factors contributing to the level of transmission of the virus, the weather appears to be significant. In this work, we analyze the impact of weather factors such as temperature, relative humidity, wind speed, and ground-level ozone concentration on the number of COVID-19 cases in Warsaw, Poland. The obtained results show an inverse correlation between ground-level ozone concentration and the daily number of COVID-19 cases.
\end{abstract}

Keywords Coronavirus $\cdot$ SARS-CoV-2 $\cdot$ Poland $\cdot$ Weather $\cdot$ Ozone

\section{Introduction}

COVID-19 is a disease caused by the novel viral agent SARSCoV-2. It was first identified and described in central China (Wuhan, Hubei Province) in December 2019. The World Health Organization announced COVID-19 outbreak a pandemic on March 12, 2020. Until now (September 10, 2020), over 27 million cases and nearly 900,000 deaths caused by this disease were reported worldwide. In Poland, these rates amounted to over 70,000 cases and over 2000 deaths. Each COVID-19 case follows an individual course. Most infected people develop symptoms that can be described as mild to moderate. Such people recover without hospitalization. However, severe symptoms of the disease are shortness of breath, high fever, cough, loss of sense of smell, and muscle pain. The mean incubation period of SARS-CoV-2 was estimated to be 6.4 days, ranging from 2.1 to 11.1 days (Lauer et al. 2020).

The first case of the novel coronavirus in Poland was reported on March 4, 2020 (in the western region of the

Oskar Wiśniewski

owisniew@doktorant.umk.pl

1 Department of Immunology, Nicolaus Copernicus University in Torun, 1 Lwowska Street, Torun, Poland

2 ImmQuest, 17 Uniwersytecka Street, Toruń, Poland country). The Polish government declared the state of epidemic threat on March 14, 2020, and the state of epidemic was declared on March 20, 2020. At this time, many restrictions were introduced, such as the obligation to wear face masks, a ban on gathering and moving in groups, and the closure of certain service points. It was also recommended not to travel for Easter and the long weekend (in the beginning of May).

It is widely known that weather conditions can influence the transmission of various viruses. Bi et al. (2007) found an inverse association between the number of daily cases of SARS and ambient temperature, and a positive association with air pressure during the epidemic of 2003 in Beijing and Hong Kong. Moreover, several epidemiological analyses identified absolute humidity and temperature as climatic predictors of influenza virus transmission in temperate regions of the world (Lowen and Steel 2014). The mechanisms by which weather factors shaping the viral transmissibility remain unclear. Possible explanations consider the instability of some viruses at high temperatures, better adhesion to objects at higher humidity, and higher transmission during strong winds.

In the present report, we analyze the impact of daily average temperature, relative humidity, wind speed, and groundlevel ozone concentration on the number of daily COVID-19 cases. As far as we know, our work is the first to consider the impact of weather factors on SARS-CoV-2 transmission in Poland. 


\section{Methods}

\section{Study area}

Warsaw is the capital of the Republic of Poland. It is located in the central-eastern part of the country $\left(52^{\circ} 14^{\prime} 13.3764^{\prime \prime} \mathrm{N}\right.$, $21^{\circ} 1^{\prime} 3.1152^{\prime \prime} \mathrm{E}$ ), in the area of humid continental climate (Köppen climate classification). According to data from December 31, 2019, it is inhabited by $1,790,658$ people and its area covers $517.24 \mathrm{~km}^{2}$ (including the Vistula river).

\section{Data collection}

Data on the daily number of cases (confirmed by the RT-PCR method) between April 7, 2020, and June 7, 2020, were obtained from the official reports of the District SanitaryEpidemiological Station in Warsaw. The weather data from April 1, 2020, to June 1, 2020: daily average temperature $\left[{ }^{\circ} \mathrm{C}\right]$, relative humidity [\%], and wind speed $[\mathrm{m} / \mathrm{s}]$ for the period of 2 months were obtained from the publicly available repository of Polish Institute of Meteorology and Water Management (Warszawa-Bielany weather monitoring station). The daily ground-level ozone $\left(\mathrm{O}_{3}\right)\left[\mu \mathrm{g} / \mathrm{m}^{3}\right]$ measurements were obtained from the publicly available database of the Chief Inspectorate of Environmental Protection (WarszawaChroscickiego air pollution monitoring station). Data on confirmed daily cases were paired with weather data 7 days earlier (due to reasons described below).

\section{Data analysis}

Since the data were not normally distributed, the Spearman rank correlation test was used to examine the relationship between particular weather factors and daily COVID-19 cases.

\section{Results and discussion}

Between April 7, 2020, and June 7, 2020, a total number of 917 COVID-19 cases were reported in Warsaw. The lowest daily average temperature recorded in the period between April 1, 2020, and June 1,2020 , was $3.9^{\circ} \mathrm{C}$, while the highest daily average temperature was $20.1^{\circ} \mathrm{C}$. The lowest daily relative humidity recorded was $35.5 \%$, while the highest daily relative humidity was $87 \%$. The lowest wind speed recorded was $1 \mathrm{~m} / \mathrm{s}$, while the highest wind speed was $5.7 \mathrm{~m} / \mathrm{s}$. The lowest daily average ground-level $\mathrm{O}_{3}$ concentration recorded was $53.9 \mu \mathrm{g} / \mathrm{m}^{3}$, while the highest ground-level $\mathrm{O}_{3}$ concentration was $97.9 \mu \mathrm{g} / \mathrm{m}^{3}$. Changes of respective values over time are presented in Fig. 1.

The obtained data indicate that only the average daily ambient ozone concentration is inversely correlated with the
Fig. 1 Daily cases of the COVID-19, daily average temperature $\left[{ }^{\circ} \mathrm{C}\right]$, relative humidity $[\%]$, wind speed $[\mathrm{m} / \mathrm{s}]$, and average ground-level zone concentration $\left[\mu \mathrm{g} / \mathrm{m}^{3}\right]$ in Warsaw, Poland, from April 7 to June 7, 2020 (number of COVID-19 cases) and April 1 to June 1, 2020 (weather variables)

number of COVID-19 cases (Table 1). Pairing of the daily case numbers with the weather conditions 7 days earlier is in our opinion corresponds more to reality than comparing the case numbers and the weather conditions on the same day. It was done due to the average incubation period of the coronavirus and the average 24-h waiting period for the RT-PCR test result in Poland.

There is a number of publications describing the impact of weather conditions on the spread of the novel coronavirus. Tosepu et al. (2020) found that only daily average temperature was significantly correlated with number of COVID-19 cases in Jakarta. Luo et al. (2020) reported a positive correlation between absolute humidity and case increase, and a weak negative correlation between weather temperature and case increase in several regions in Asia. A study on the effects of temperature and humidity on the daily new cases and new deaths of COVID-19 in 166 countries revealed that both factors were negatively related to the daily new cases and daily new deaths of COVID-19 (Wu et al. 2020). Poirier et al. (2020) indicated that higher temperatures and locations with higher absolute humidity appeared to have lower COVID-19 transmission. The authors have also identified potential confounders, suggesting that changes in weather alone may not lead to changes in case count without the implementation of public health interventions. Jiwei et al. (2020) proposed that a decrease in the transmissibility of COVID-19 is likely with the arrival of spring in the north hemisphere. However, temperature and humidity were found to contribute to a maximum of $18 \%$ of the variation, the remaining $82 \%$ to social factors. In their study, Bu et al. (2020) found that the suitable temperature range for SARS-CoV-2 survival is $13-24{ }^{\circ} \mathrm{C}$. Unfortunately, the authors have not identified any confounders and potential strategies to deal with them. Shi et al. (2020) in their retrospective observational study concluded that both low and high temperatures might decrease the COVID-19 incidence, but the duration of the outbreak would depend on the safety measures introduced by particular countries. Ran et al. (2020b) found that the ambient temperature has a nonlinear negative association with COVID-19 transmission. It is also remarked that control strategies for the COVID-19 pandemic barely relying on environmental factors are unlikely to succeed. On the other hand, Yao et al. (2020) showed no association of COVID-19 transmission with temperature or UV radiation in China.

Only a few papers describe the effects of ambient ozone concentration on COVID-19. A recent paper from China shows that the COVID-19 transmissibility could be negatively associated with ambient ozone (Ran et al. 2020a). On the 

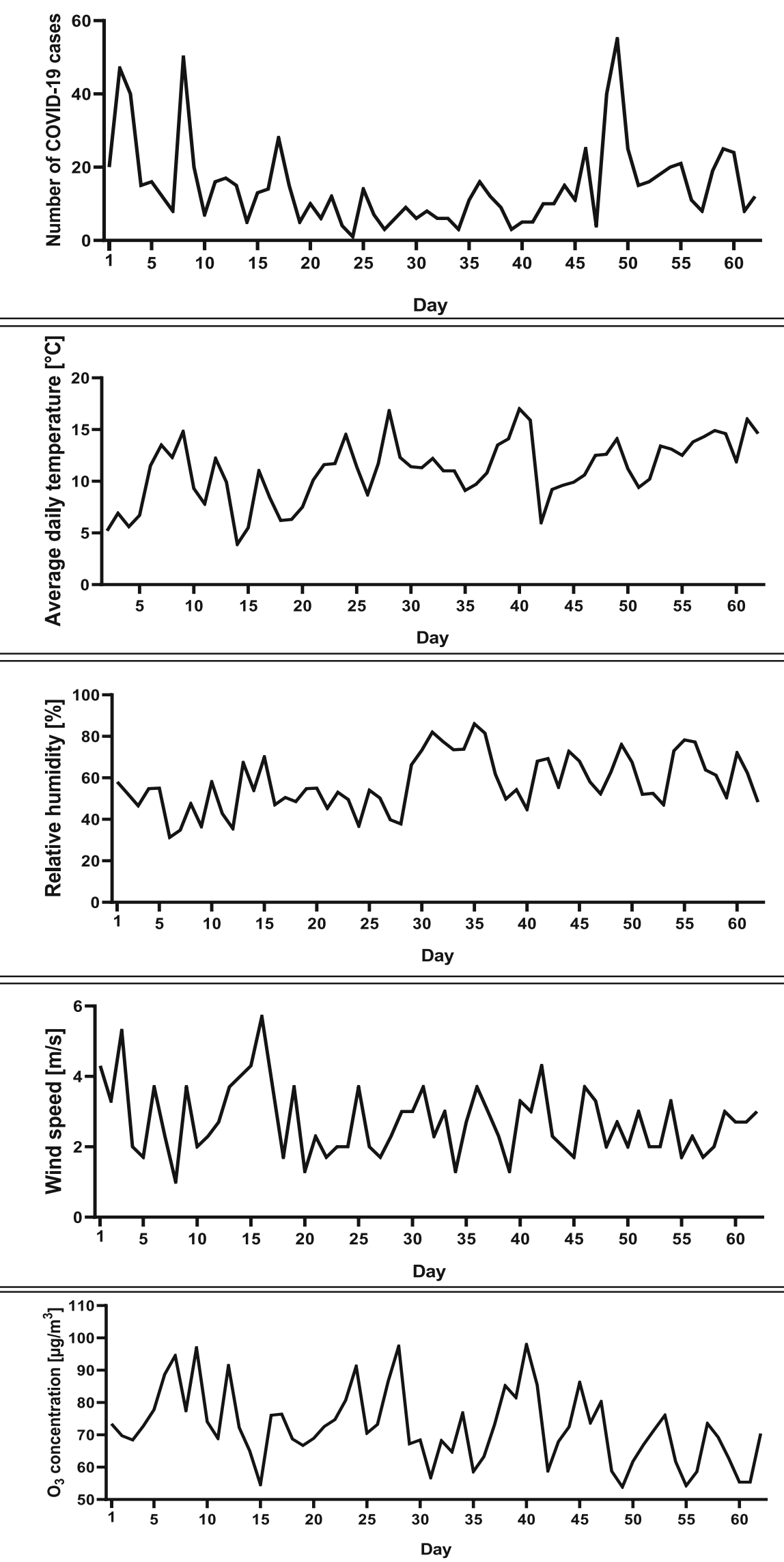
Table 1 Spearman correlation coefficients $(\rho)$ and their $P$-values between COVID-19 cases and weather variables

\begin{tabular}{lll}
\hline Weather variable & Spearman's $\rho$ & $P$-value \\
\hline Average daily temperature $\left[{ }^{\circ} \mathrm{C}\right]$ & -0.1195 & 0.3589 \\
Relative humidity $[\%]$ & 0.0389 & 0.7636 \\
Wind speed $[\mathrm{m} / \mathrm{s}]$ & 0.1355 & 0.2937 \\
Ground-level ozone concentration $\left[\mu \mathrm{g} / \mathrm{m}^{3}\right]$ & $-0.2997 *$ & 0.0180 \\
\hline
\end{tabular}

*Correlation is significant at the 0.05 level (two-tailed)

contrary, a positive correlation was found between COVID-19 infections and ground-level ozone in Milan, Italy (Zoran et al. 2020). An analysis performed by Adhikari and Yin (2020) showed that daily average temperature, daily maximum 8 -h ozone concentration, average relative humidity, and cloud percentages were significantly and positively associated with new confirmed cases related to COVID-19, but none of these variables showed significant associations with new deaths related to COVID-19.

Ozone is generally considered an antiviral agent that damages the viral capsid and upsets its reproductive cycle (Elvis and Ekta 2011). However, a review of the literature shows that ozone doses that have a virucidal effect range from 0.6 to $6.0 \mathrm{ppm}$ for 20-112 min (Tseng and Li 2008; Yano et al. 2020). Commercial ozone generators guaranteed antiviral efficacy at 10-20 ppm for $10 \mathrm{~min}$ (Dennis et al. 2020; Grignani et al. 2021). It is therefore clear that the ambient ozone levels are several orders of magnitude lower than the doses used to eliminate respiratory viruses. However, we propose a mechanism that may explain the inverse correlation described above based on alterations of immune system functions. There are a number of reports suggesting that both innate and acquired immunity are regulated by ambient ozone. In general, environmental ozone modifies cell types required for priming innate immunity and contributes to innate-adaptive immune system cross-talk (Al-Hegelan et al. 2011). The alterations are visible both in the number and type of cells of the immune system and in the substances produced by these cells. For example, increased level of ambient ozone was found to activate innate immune signaling in airway epithelia (Gribar et al. 2008) and to suppress T-lymphocyte-dependent immune response (Al-Hegelan et al. 2011). Moreover, changes in production of proteins involved in immune signaling (interleukin1 , interleukin-6, interleukin-17, and tumor necrosis factor $\alpha$ ) were observed (Al-Hegelan et al. 2011). We propose that the activity of another cytokine, interleukin-33, could be a potential explanation of the observed inverse correlation. According to the literature, interleukin-33 is induced by ozone and further activates Th2 phenotype cytokines in the respiratory tract (Ali et al. 2018). On the other hand, there is an emerging evidence that Th2-skewed immunity might be protective in COVID-19 patients. This phenotype is able to downregulate the late phase of disease which is typically associated with uncontrolled inflammation (Carli et al. 2020). The protective role of Th2 phenotype is probably mainly due to the eosinophils. Increase in the number and activation of these cells have traditionally been linked to allergies and asthma, but it turns out that eosinophils, besides their proinflammatory effects, play a crucial role in antiviral responses (Franceschini et al. 2020). Our candidate, interleukin-33, regulates eosinophils at three stages: development within the bone narrow, activation of matured cells, and activation of mature eosinophils within the tissue (Johnston and Bryce 2017). Therefore, we suggest that the increased activity of interleukin-33 under the influence of ambient ozone may be responsible for the creation of an immune microenvironment that protects against SARSCoV-2 infection.

It must be emphasized that our research has some limitations. Firstly, the number of COVID-19 cases may not be directly related to virus transmission. In the described period, the Polish government did not provide the daily number of tests performed, but only informed about the number of positive cases. Moreover, we suspect that asymptomatic or oligosymptomatic cases may have missed the tests for fear of worsening the quality of life (due to quarantine or domestic isolation). Secondly, confounding variables must be taken into consideration. General health policies for a given period, containment measures, public health interventions, population density, and cultural aspects - all of these can contribute to the spread of the virus. Warsaw, as the largest city in the country, is the main communication hub, and the mobility of its inhabitants is at a high level — many of them are commuters from surrounding regions. The inhabitants are characterized by different hygienic habits, lifestyle, profession, etc. Thus, we believe that weather factors cannot be considered separately from social factors.

\section{Conclusions}

Of the factors studied, only ozone concentration seems to have an impact on the number of new COVID-19 cases. Further research is needed, for example, in other Polish cities, to characterize the remaining weather factors that may influence the spread of the virus.

Acknowledgements The authors are grateful to Dr. Maciej Wachulec, who supported and encouraged this research.

Data availability The datasets analyzed during the current study are available in the IMGW repository (temperature, humidity, wind speed) (https://www.imgw.pl/en) and GIOS repository (ozone) (http:// powietrze.gios.gov.pl/pjp/current). 


\section{Declarations}

Conflict of interest The authors declare no competing interests.

Open Access This article is licensed under a Creative Commons Attribution 4.0 International License, which permits use, sharing, adaptation, distribution and reproduction in any medium or format, as long as you give appropriate credit to the original author(s) and the source, provide a link to the Creative Commons licence, and indicate if changes were made. The images or other third party material in this article are included in the article's Creative Commons licence, unless indicated otherwise in a credit line to the material. If material is not included in the article's Creative Commons licence and your intended use is not permitted by statutory regulation or exceeds the permitted use, you will need to obtain permission directly from the copyright holder. To view a copy of this licence, visit http://creativecommons.org/licenses/by/4.0/.

\section{References}

Adhikari A, Yin J (2020) Short-Term Effects of Ambient Ozone, PM2. 5, and Meteorological Factors on COVID-19 Confirmed Cases and Deaths in Queens, New York. Int J Environ Res Public Health 17(11):4047. https://doi.org/10.3390/ijerph17114047

Al-Hegelan M, Tighe RM, Castillo C, Hollingsworth JW (2011) Ambient ozone and pulmonary innate immunity. Immunol Res 49(1-3):173191. https://doi.org/10.1007/s12026-010-8180-Z

Ali ST, Wu P, Cauchemez S, He D, Fang VJ, Cowling BJ, Tian L (2018) Ambient ozone and influenza transmissibility in Hong Kong. Eur Respir J 51(5):1800369. https://doi.org/10.1183/13993003.003692018

Bi P, Wang J, Hiller JE (2007) Weather: driving force behind the transmission of severe acute respiratory syndrome in China? Intern Med J 37(8):550-554. https://doi.org/10.1111/j.1445-5994.2007.01358.x

Bu J, Peng DD, Xiao H, Yue Q, Han Y, Lin Y, Hu G \& Chen J. (2020). Analysis of meteorological conditions and prediction of epidemic trend of 2019-nCoV infection in 2020. MedRxiv 2020.02.13.20022715, DOI: https://doi.org/10.1101/2020.02.13. 20022715

Carli G, Cecchi L, Stebbing J, Parronchi P, Farsi A (2020) Is asthma protective against COVID-19? Allergy 76:866-868. https://doi. org/10.1111/all.14426

Dennis R, Cashion A, Emanuel S, \& Hubbard D (2020). Ozone Gas: Scientific Justification and Practical Guidelines for Improvised Disinfection using Consumer-Grade Ozone Generators and Plastic Storage Boxes. J Sci Med 2(1), https://doi.org/10.37714/josam.v2i1. 35

Elvis AM, Ekta JS (2011) Ozone therapy: A clinical review. J Nat Sci Biol Med 2(1):66. https://doi.org/10.4103/0976-9668.82319

Franceschini L, Macchiarelli R, Rentini S, Biviano I, Farsi A (2020) Eosinophilic esophagitis: is the Th2 inflammation protective against the severe form of COVID-19? Eur J Gastroenterol Hepatol 32(12): 1583. https://doi.org/10.1097/MEG.0000000000001909

Gribar SC, Richardson WM, Sodhi CP, Hackam DJ (2008) No longer an innocent bystander: epithelial toll-like receptor signaling in the development of mucosal inflammation. Mol Med 14(9):645-659. https://doi.org/10.2119/2008-00035.Gribar

Grignani E, Mansi A, Cabella R, Castellano P, Tirabasso A, Sisto R, Spagnoli M, Fabrizi G, Frigerio F, Tranfo G (2021) Safe and Effective Use of Ozone as Air and Surface Disinfectant in the Conjuncture of Covid-19. Gases 1(1):19-32. https://doi.org/10. 3390/gases 1010002
Jiwei J, Ding J, Liu S, Liao G, Li J, Duan B, Wang G, Zhang R (2020) Modeling the control of COVID-19: Impact of policy interventions and meteorological factors. Electron J Diff Equat 23:1-24

Johnston LK, Bryce PJ (2017) Understanding interleukin 33 and its roles in eosinophil development. Front Med 4:51. https://doi.org/10.3389/ fmed.2017.00051

Lauer SA, Grantz KH, Bi Q, Jones FK, Zheng Q, Meredith HR, Azman AS, Reich NG, Lessler J (2020) The incubation period of coronavirus disease 2019 (COVID-19) from publicly reported confirmed cases: estimation and application. Ann Intern Med 172(9):577582. https://doi.org/10.7326/M20-0504

Lowen AC, Steel J (2014) Roles of humidity and temperature in shaping influenza seasonality. J Virol 88(14):7692-7695. https://doi.org/10. 1128/JVI.03544-13

Luo W, Majumder M, Liu D, Poirier C, Mandl K, Lipsitch M, \& Santillana M (2020). The role of absolute humidity on transmission rates of the COVID-19 outbreak, medRxiv 2020.02.12.20022467, DOI: https://doi.org/10.1101/2020.02.12.20022467

Poirier C, Luo W, Majumder MS, Liu D, Mandl KD, Mooring TA, Santillana M (2020) The role of environmental factors on transmission rates of the COVID-19 outbreak: an initial assessment in two spatial scales. Sci Rep 10(1):1-11. https://doi.org/10.1038/s41598020-74089-7

Ran J, Zhao S, Han L, Chen D, Yang Z, Yang L, Wang M, H., \& He, D. (2020a) The ambient ozone and COVID-19 transmissibility in China: A data-driven ecological study of 154 cities. J Infect 81(3): e9-e11. https://doi.org/10.1016/j.jinf.2020.07.011

Ran J, Zhao S, Han L, Liao G, Wang K, Wang MH, He D (2020b) A reanalysis in exploring the association between temperature and COVID-19 transmissibility: an ecological study with 154 Chinese cities. Eur Respir J 56(2):2001253. https://doi.org/10.1183/ 13993003.01253-2020

Shi P, Dong Y, Yan H, Li X, Zhao C, Liu W, He M, Tang S \& Xi S (2020). The impact of temperature and absolute humidity on the coronavirus disease 2019 (COVID-19) outbreak-evidence from China. MedRxiv 2020.03.22.20038919, DOI: https://doi.org/10. $1101 / 2020.03 .22 .20038919$

Tosepu R, Gunawan J, Effendy DS, Lestari H, Bahar H, Asfian P (2020) Correlation between weather and Covid-19 pandemic in Jakarta, Indonesia. Sci Total Environ 725:138436. https://doi.org/10.1016/ j.scitotenv.2020.138436

Tseng C, Li C (2008) Inactivation of surface viruses by gaseous ozone. J Environ Health 70(10):56-62

Wu Y, Jing W, Liu J, Ma Q, Yuan J, Wang Y, Du M, Liu M (2020) Effects of temperature and humidity on the daily new cases and new deaths of COVID-19 in 166 countries. Sci Total Environ 729: 139051. https://doi.org/10.1016/j.scitotenv.2020.139051

Yano H, Nakano R, Suzuki Y, Nakano A, Kasahara K, Hosoi H (2020) Inactivation of severe acute respiratory syndrome coronavirus 2 (SARS-CoV-2) by gaseous ozone treatment. J Hosp infect 106(4): 837-838. https://doi.org/10.1016/j.jhin.2020.10.004

Yao Y, Pan J, Liu Z, Meng X, Wang W, Kan H, Wang W (2020) No association of COVID-19 transmission with temperature or UV radiation in Chinese cities. Eur Respir J 55(5):2000517. https://doi. org/10.1183/13993003.00517-2020

Zoran MA, Savastru RS, Savastru DM, Tautan MN (2020) Assessing the relationship between ground levels of ozone $(\mathrm{O} 3)$ and nitrogen dioxide (NO2) with coronavirus (COVID-19) in Milan, Italy. Sci Total Environ 740:140005. https://doi.org/10.1016/j.scitotenv. 2020.140005

Publisher's note Springer Nature remains neutral with regard to jurisdictional claims in published maps and institutional affiliations. 